\title{
O PAPEL DO VAPOR D’AGUA NO SISTEMA CLIMÁTICO
}

\author{
Daniela de Souza Onça ${ }^{1}$
}

\section{RESUMO}

Este trabalho discute o papel exercido pelo vapor d'água no sistema climático global, com ênfase sobre a maneira como essa substância é abordada nas discussões sobre o aquecimento global antropogênico. Veremos como o vapor d'água atua na manutenção da temperatura terrestre e como são abordados os seus mecanismos de realimentação pelo Painel Intergovernamental de Mudanças Climáticas (IPCC). Por fim, discutimos esses mecanismos com base na "hipótese íris" de Richard Lindzen, argumento pouco considerado nos debates sobre as mudanças climáticas globais.

PALAVRAS-CHAVE: Vapor d'água. Aquecimento global. Mecanismos de realimentação.

\section{THE ROLE OF WATER VAPOR IN THE CLIMATE SYSTEM}

\begin{abstract}
This paper discusses the role played by water vapor in the global climate system, emphasizing on how this substance is addressed in discussions about anthropogenic global warming. We'll see how the water vapor acts in maintaining the Earth's temperature and how their feedback mechanisms are addressed by the Intergovernmental Panel on Climate Change (IPCC). Finally, we discuss these mechanisms based on Richard Lindzen's "iris hypothesis", argument rarely considered in debates about global climate change.
\end{abstract}

KEY-WORDS: Water vapor. Global warming. Feedback mechanisms.

\section{EL PAPEL DE VAPOR DE AGUA EN EL SISTEMA CLIMÁTICO}

\footnotetext{
${ }^{1}$ Doutora em Geografia Física. Professora do Departamento de Geografia da Universidade do Estado de Santa Catarina (UDESC). danielaonca@yahoo.com.br
} 


\section{RESUMEN}

Este artículo analiza el papel desempeñado por el vapor de agua en el sistema climático global, con énfasis en cómo se aborda esta sustancia en las discusiones sobre el calentamiento global antropogénico. Vamos a ver cómo actúa el vapor de agua en el mantenimiento de la temperatura de la Tierra y cómo sus mecanismos de retroalimentación son abordados por el Grupo Intergubernamental de Expertos sobre el Cambio Climático (IPCC). Finalmente, se discuten estos mecanismos basados en "hipótesis iris" Richard Lindzen, argumento raramente considerado en los debates sobre el cambio climático global.

PALABRAS-CLAVE: El vapor de agua. Calentamiento global. Los mecanismos de retroalimentación.

\section{INTRODUÇÃO}

Poucas pessoas não versadas em Climatologia sabem que o mais importante gás estufa, ao contrário do que costuma ser apregoado, não é o dióxido de carbono, mas o vapor d'água, um gás de concentrações muito variáveis no tempo e no espaço na atmosfera. A importância atribuída a este gás para o efeito estufa global costuma variar entre $55 \%$ e $95 \%$ de acordo com os diversos autores que o consideram, números que demonstram não apenas sua importância mas também as margens de incerteza associadas aos processos em que este gás está envolvido (LEROUX, 2005, p. 85). Numa conjuntura econômica, social e política de grande destaque à temática das mudanças climáticas globais, cabe fazer um resgate desse conhecimento da importância do vapor d'água para o sistema climático, a fim de se tratar o tema mais adequadamente.

\section{O PAPEL DO VAPOR D'ÁGUA NO SISTEMA CLIMÁTICO}

A figura abaixo deixará clara essa importância, ao mostrar os diversos comprimentos de onda absorvidos pelo vapor d'água:

Figura 1 - Curva a: espectro de emissão de um corpo negro à temperatura de 6000K; curva b: irradiância solar no topo da atmosfera; curva c: irradiância solar ao nível do mar, com as áreas sombreadas representando as bandas de absorção de alguns gases atmosféricos. Note-se os diversos comprimentos de onda absorvidos pelo vapor d'água, muito mais que os do dióxido de carbono. 
da tita Paclista

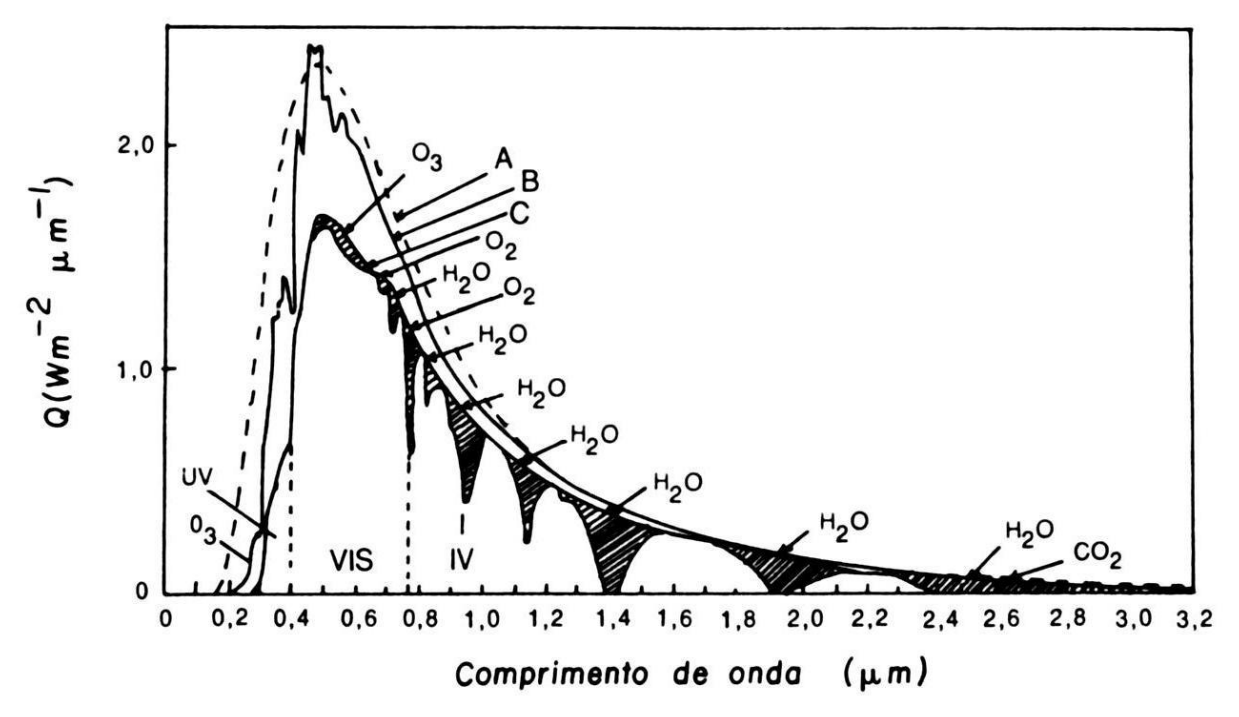

Fonte: VIANELLO; ALVES, 1991, p. 170.

Um autor que dá grande destaque ao papel do vapor d'água é Richard Lindzen, afirmando que "Mesmo que todos os outros gases estufa (como o dióxido de carbono e o metano) desaparecessem, ainda restariam 98\% do efeito estufa atual" (LINDZEN, 1992, p. 88). Diante desse papel preponderante do vapor d'água no balanço radiativo da atmosfera,

\footnotetext{
"é claramente inútil lidar com a mudança climática sem conhecimento e compreensão apropriados do comportamento dessa substância vital. Está igualmente claro que nosso conhecimento atual sobre o comportamento do vapor d'água é inadequado para esta tarefa" (LINDZEN, 1991, p. 1).
}

Apesar de esta citação de Lindzen datar do início da década de 1990, permanece bastante atual, dado que os avanços ocorridos neste ponto desde então não podem ser considerados muito significativos. Muito se critica a maneira como o IPCC lida com o papel de gás estufa exercido pelo vapor d'água e os processos envolvidos, levando alguns cientistas, como Leroux, a bradar que "na atmosfera do IPCC não há água!" (LEROUX, 2005, p. 95). Exageros à parte, a afirmativa não é de todo descabida. O papel do vapor d'água como gás estufa é tratado de maneira muito rasteira nos relatórios do IPCC. A razão para este aparente descaso pode ser 
encontrada no final do apêndice do capítulo 6 do terceiro relatório, onde se lê: "É importante enfatizar que as mudanças no vapor d'água na troposfera são vistas como um mecanismo de realimentação ao invés de um agente de forçamento" (IPCC, 2001, p. 406). Também no quarto relatório, podemos ler: "Apesar do vapor d'água ser um forte gás estufa, sua concentração na atmosfera muda em resposta a mudanças no clima da superfície e isso deve ser considerado um mecanismo de realimentação e não um forçamento radiativo" (IPCC, 2007, p. 23).

Comecemos pelo que o IPCC denomina "o bem conhecido mecanismo de realimentação positiva do vapor d'água". Todos os modelos concordam que a tendência de elevação das temperaturas provocada pelo dióxido de carbono resultará em maior evaporação da água, umidificando a atmosfera e amplificando a tendência de aquecimento. Na baixa troposfera, a condensação do vapor d'água para formar a precipitação libera calor latente, que domina a estrutura do aquecimento adiabático troposférico. Sua concentração diminui rapidamente com a altitude, mas é justamente esta baixa concentração quem contribui para o efeito estufa natural. O vapor d'água é a maior fonte de opacidade à radiação infravermelha na atmosfera; sua presença na média e alta troposfera responde por cerca de $60 \%$ do efeito estufa natural sob céu claro, e fornece os maiores mecanismos de realimentação positiva nas projeções de mudanças climáticas: sozinho, ele quase dobra o aquecimento em resposta a um forçamento inicial. A absorção de radiação de onda longa aumenta aproximadamente com o logaritmo da concentração de vapor d'água, enquanto a equação de ClausiusClayperon dita uma elevação quase exponencial na capacidade de retenção de umidade com a temperatura. Isso significa um forte mecanismo de realimentação do vapor d'água se a umidade relativa é mantida constante, ou seja, um aquecimento inicial na superfície leva a um rápido aquecimento na alta troposfera (SPENCER, 2008, p. 70; IPCC, 2007, p. 271, 273, 632-633).

De acordo com o IPCC, foram feitos progressos significativos desde o TAR, e já existe grande confiança no desempenho dos GCMs em simular o mecanismo de realimentação do vapor d'água na camada limite, bem como na zona extratropical, pois os distúrbios de grande escala, responsáveis por muito da distribuição de umidade pela troposfera, são hoje bem simulados. Na média e alta troposfera 
tropicais, entretanto, os modelos ainda deixam a desejar, pois as mudanças de umidade são menos compreendidas e apresentam maior impacto radiativo no topo da atmosfera do que ocorre em outras regiões (IPCC, 2007, p. 633).

A distribuição de umidade na troposfera livre tropical é determinada por muitos fatores, incluindo o descarregamento de vapor d'água condensado de sistemas convectivos e da circulação atmosférica de grande escala. As regiões de subsidência relativamente secas desempenham um papel fundamental no resfriamento de onda longa tropical, e mudanças em sua área ou umidade podem ter um impacto significativo na intensidade do mecanismo de realimentação do vapor d'água. Dada a complexidade dos processos que controlam a umidade na região tropical, no entanto, argumentos físicos simples sobre mudanças sob um aquecimento em escala global são de difícil sustentação, e faz-se necessária uma combinação de modelagem e estudos observacionais para avaliar a confiabilidade do mecanismo de realimentação modelado (IPCC, 2007, p. 633).

Os GCMs apresentam como característica marcante um forte sinal positivo no mecanismo de realimentação do vapor d'água, sendo encontrado em modelos com esquemas muito diferentes para advecção, convecção e condensação do vapor d'água. Modelos de mesoescala em alta resolução e de resolução de nuvens rodados em regiões tropicais limitadas também exibem respostas na umidade consistentes com uma realimentação fortemente positiva, embora com diferenças nos detalhes das tendências de umidade relativa na alta troposfera com a temperatura. Experimentos com GCMs descobriram que a intensidade do mecanismo de realimentação do vapor d'água é insensível a grandes mudanças na resolução vertical, bem como a esquemas de parametrização convectiva e advectiva. Tais estudos de modelagem fornecem evidências de que a resposta da umidade relativa na troposfera livre de modelos a um aquecimento do clima não é um simples artefato dos GCMs ou de sua resolução, posto que mudanças similares são encontradas em uma gama de modelos de diferentes complexidades e escopos (IPCC, 2007, p. 633).

No entanto, existem algumas fortes razões para se questionar a intensidade da amplificação do aquecimento por este mecanismo. Lindzen discordará visceralmente dessas considerações sobre o efeito amplificador do aquecimento relacionado ao 
vapor d'água. O esquema do balanço radiativo terrestre, nossa imagem habitual do papel exercido pelos gases estufa para a efetiva temperatura do planeta, dirá o autor, é profundamente incompleto. De acordo com Lindzen, se a temperatura do planeta fosse determinada puramente por processos radiativos, ela seria de cerca de $77^{\circ} \mathrm{C}$, e não de $15^{\circ} \mathrm{C}$. Nossa efetiva temperatura está, portanto, muito mais próxima da temperatura de corpo negro $\left(-18^{\circ} \mathrm{C}\right)$ do que a resultante de um efeito estufa puro. Não queremos dizer com isso que o efeito estufa não existe - afinal de contas, $15^{\circ} \mathrm{C}$ é uma temperatura superior a $-18^{\circ} \mathrm{C}$-, mas apenas que sua importância para a determinação da temperatura do planeta não é tão grande quanto se costuma apregoar. Na verdade, também estão ativos processos de condução e convecção (transporte pelo movimento do ar), que desviam muito da absorção radiativa, transportando o excedente energético da região tropical em direção aos pólos e altitudes mais altas, principalmente através dos movimentos convectivos de nuvens do tipo Cumulonimbus, pela circulação de Hadley e por distúrbios baroclínicos para latitudes e altitudes mais altas, onde o potencial de aquecimento estufa (opacidade à radiação infravermelha) é bem menor, conforme pode ser visualizado na figura a seguir (LINDZEN, 1990a, p. 293-295; 1990b, p. 425; 1990c, p. 46; 1991, p. 2-3; 1992, p. 88):

Figura 2 - Representação esquemática da opacidade infravermelha da atmosfera por latitude e altitude. A opacidade à radiação infravermelha é maior próximo ao solo e nos trópicos, e diminui conforme nos dirigimos para os pólos e para altitudes mais altas. As correntes de ar transportam energia para essas regiões de opacidade reduzida, de onde ela é irradiada para o espaço, contribuindo para o resfriamento do planeta. Infelizmente, essas regiões da atmosfera ainda são, comparativamente, menos conhecidas. 


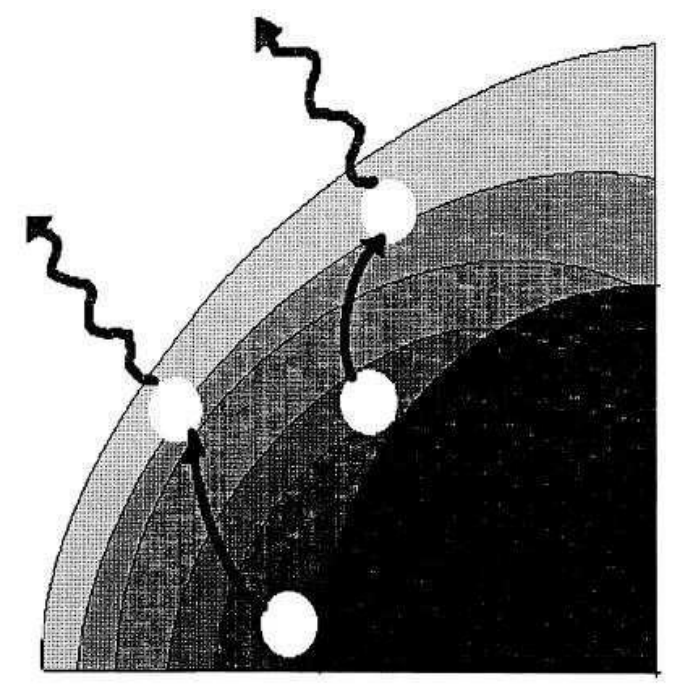

Fonte: LINDZEN, 1991, p. 15.

A linha pontilhada na figura abaixo mostra como a temperatura da troposfera mudaria com a altitude se dependesse unicamente do efeito estufa. A temperatura média da superfície da Terra, de acordo com Spencer, seria de $60^{\circ} \mathrm{C}$ (notemos que Lindzen fornece um valor diferente). Mas muito antes de essa temperatura ser atingida, a atmosfera se torna convectivamente instável, com o ar quente da superfície subindo e $\mathrm{o}$ ar frio descendo, transportando o excedente de energia da superfície para as altas altitudes. A região sombreada na parte baixa da figura representa quanto do decréscimo de temperatura é causado na baixa troposfera pelos fenômenos meteorológicos. Já a região hachurada na alta troposfera representa o acréscimo de temperatura que resulta do transporte de energia pelos fenômenos meteorológicos. Enquanto todos nós já ouvimos falar que "o efeito estufa torna a Terra quente o suficiente para ser habitada", poucas vezes ouvimos - se é que ouvimos - dizer que "os fenômenos meteorológicos tornam a Terra fria o suficiente para ser habitada” (SPENCER, 2008, p. 53-54). 
Figura 3 - Perfil de redução da temperatura troposférica com a altitude pelo efeito estufa natural (teoria, linha tracejada) e pelo estufa natural somado aos fenômenos meteorológicos (observado, linha contínua).

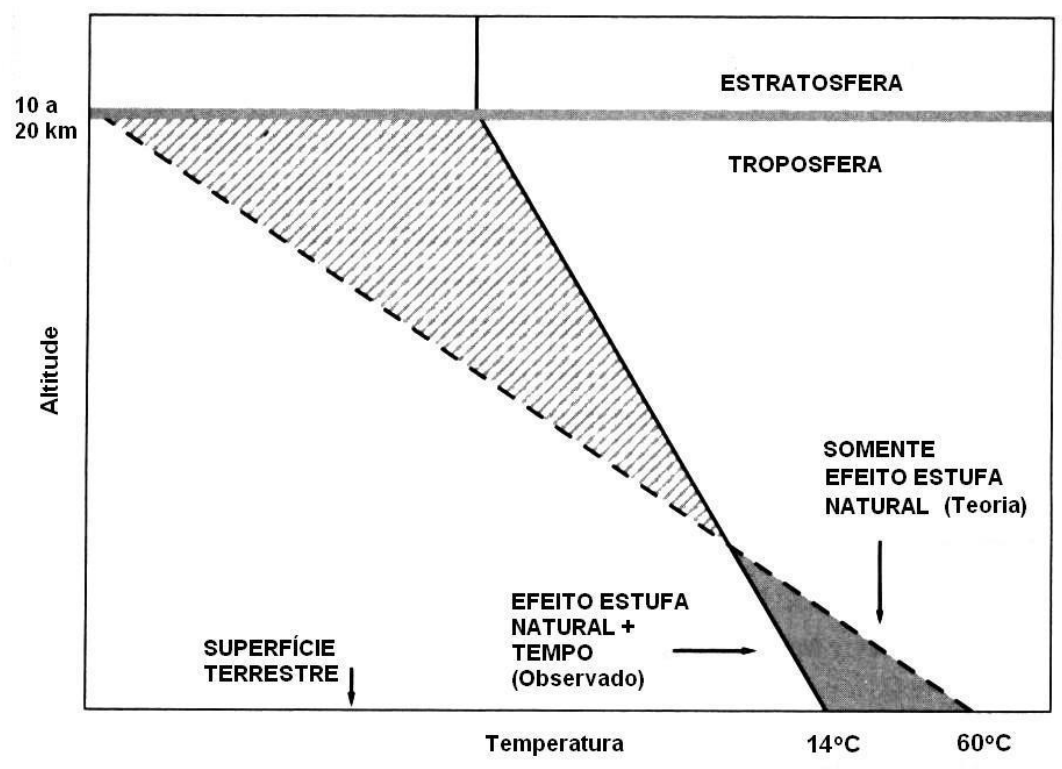

Fonte: SPENCER, 2008, p. 53.

E qual será o processo responsável por esse resfriamento do planeta? Será a perda de calor latente da superfície através da evaporação da água. Pelo menos 90\% da energia perdida pelos lagos e oceanos se dá através da absorção de energia necessária para a passagem da água do estado líquido para o estado gasoso. Em terra, muito dessa perda energética se dá através da evapotranspiração das plantas (SPENCER, 2008, p. 56-57).

Sim, o vapor d’água atmosférico representa tanto um fator de aquecimento quanto de resfriamento do planeta. Quando a água da superfície é evaporada, remove energia; então, o vapor d'água formado ajuda a aquecer a superfície através do efeito estufa. Ambos os efeitos estão ocorrendo ao mesmo tempo, continuamente. Sim, a água é uma substância com uma grande variedade de funções no sistema climático (SPENCER, 2008, p. 57). 
O efeito estufa devido ao vapor d'água não é controlado pela evaporação da superfície, mas pelos sistemas de precipitação. A quantidade de vapor d'água na média e alta troposfera - as camadas que mais contribuem para o efeito estufa natural - é controlada por processos complexos em sistemas de precipitação. Muito embora a evaporação da superfície tente encher a atmosfera de vapor d'água, a precipitação impede que isso aconteça. A precipitação, em outras palavras, controla o efeito estufa natural e, por conta desse controle, não podemos saber efetivamente quanto irá aumentar o conteúdo de vapor d'água na atmosfera em razão de uma elevação das temperaturas sem efetivamente compreendermos como os sistemas de precipitação mudarão sua eficiência na remoção de vapor d'água da atmosfera (SPENCER, 2008, p. 70-71).

Para sustentá-la, o autor explica o funcionamento das nuvens de tipo Cumulonimbus, esquematizado na figura abaixo. Elas consistem em altas torres de ar ascendente, que se resfria nesse movimento, provocando a condensação do vapor d'água e sua queda na forma de chuva, de modo que quando essas nuvens atingem sua altitude máxima (por vezes $16 \mathrm{~km}$ ), seu ar já está relativamente seco. No entanto, esses movimentos ascendentes não podem existir sem que haja movimentos subsidentes no entorno para compensá-los; essa subsidência atua no sentido de preencher a atmosfera acima de 3 ou $5 \mathrm{~km}$ de altitude com ar mais seco. Dessa forma, caso ocorra um aquecimento do planeta, a atmosfera acima de $5 \mathrm{~km}$ se tornaria mais seca - e não mais úmida, conforme sugere a maioria dos modelos - e a convecção seria intensificada, elevando a altitude onde a energia seria liberada. Ambos os processos são mecanismos de realimentação negativa, e poderiam diminuir o efeito do aquecimento devido ao dióxido de carbono, ao invés de incrementá-lo, como normalmente é sugerido. No final das contas, a realimentação associada ao vapor d'água seria negativa, e não positiva, conforme acredita o IPCC (LINDZEN, 1990a, p. 296-297; 1990b, p. 425; 1991, p. 6-9). 
Figura 4 - Representação esquemática de uma nuvem Cumulonimbus e dos processos envolvidos.

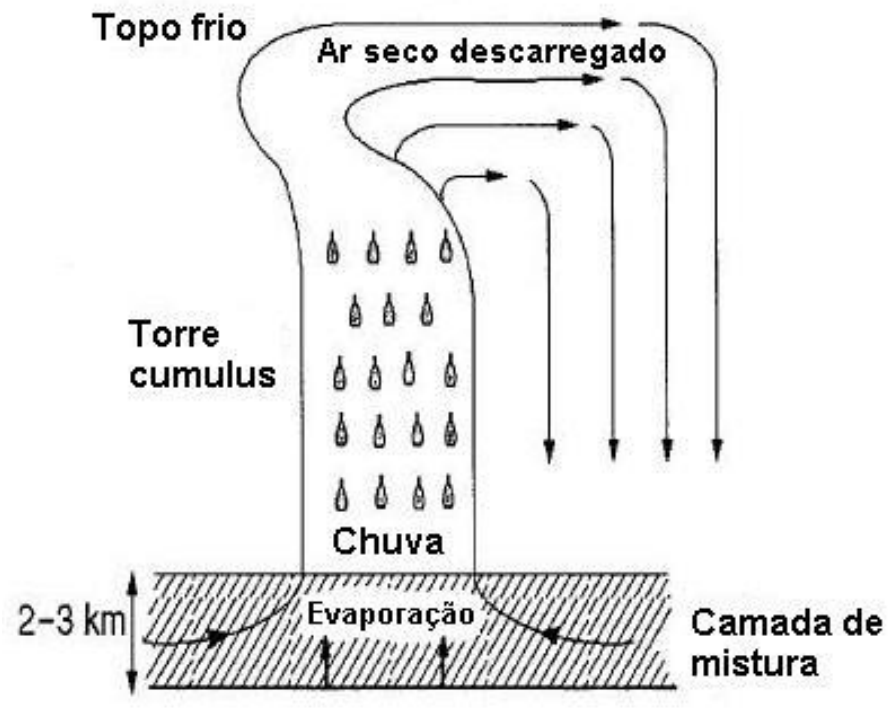

Fonte: LINDZEN, 1990a, p. 297.

Lindzen denomina esse mecanismo de efeito íris, uma analogia à íris ocular que abre e fecha para permitir maior ou menor passagem de luz. Ao "abrir" e "fechar" as regiões livres de nuvens de altos níveis, que permitem um resfriamento radiativo mais eficientemente, este mecanismo controlaria mudanças de temperatura na superfície tropical. A equipe de Lindzen publicou um estudo empírico sobre esse efeito em 2001, examinando a cobertura de nuvens no oeste do Pacífico (a região entre $30^{\circ} \mathrm{N}-30^{\circ} \mathrm{S}$ e $130^{\circ} \mathrm{L}-170^{\circ} \mathrm{O}$ ) entre $1^{\circ}$ de janeiro de 1998 e 31 de agosto de 1999. Sua conclusão é de que o efeito íris mais do que cancela os mecanismos de realimentação positiva postulados pelo IPCC, reduzindo a amplitude de estimativas da sensitividade climática do dióxido de carbono de $1,5^{\circ} \mathrm{C}$ a $4^{\circ} \mathrm{C}$ (no AR $4,1,2^{\circ} \mathrm{C}$ a $4^{\circ} \mathrm{C}$ ) para apenas $0,64^{\circ} \mathrm{C}$ a $1,6^{\circ} \mathrm{C}$, reduzindo drasticamente as previsões de um aquecimento global catastrófico. Também está envolvida nesta baixa sensitividade climática a alta reflexão da radiação solar pelos topos muito brancos dos Cumulonimbus. Caso o efeito íris seja provado tão eficiente quanto os resultados da pesquisa sugerem, a incapacidade dos modelos atuais em replicar essas relevantes observações sugere a necessidade de melhoramento dos modelos numa área crucial 
para a determinação da sensitividade climática (LINDZEN; CHOU; HOU, 2001, p. 421, 429-431).

Sabemos bem que esses processos de transporte de energia envolvendo o vapor d'água não são ainda suficientemente bem simulados pelos modelos disponíveis; sob tais circunstâncias, podemos nos perguntar como os atuais modelos conseguem simular as temperaturas do planeta e 0 sistema climático adequadamente. A resposta de Lindzen é a de que eles simplesmente não conseguem. O próprio IPCC reconhece essa inconveniência em diversos momentos, embora de maneira muito discreta. Como o ciclo do vapor d'água nas nuvens, mais especificamente em sistemas convectivos, ainda é fracamente compreendido, os papéis do vapor d'água e das nuvens não são bem representados nos modelos climáticos; como resultado, ainda persistem, e persistirão por muitos anos, grandes incertezas sobre a atuação desse gás (LINDZEN, 1991, p. 3-4; LEROUX, 2005, p. 85).

\section{CONCLUSÃO}

Apesar da falta de compreensão, o consenso entre os global warmers continua sendo o de que o mecanismo de realimentação da água é fortemente positivo e solidamente compreendido. Contudo, não há dúvida de que uma variedade de elementos envolvidos nos sistemas de precipitação pode alterar, pelo menos teoricamente, a resposta do sistema climático a um aquecimento, seja ele induzido pelo dióxido de carbono ou não. Também não resta dúvida de que os modelos atualmente disponíveis não simulam tais sistemas de maneira satisfatória (SPENCER, 2008, p. 71-72). A única dúvida que resta é por que o IPCC e seus partidários continuam acreditando que esses mesmos modelos são capazes de prever como será o clima da Terra daqui a cem anos. 


\section{REFERÊNCIAS}

IPCC. Climate change 2001: the scientific basis. Cambridge, New York; Cambridge University Press, 2001.

Climate change 2007: the physical science basis. Cambridge, New York; Cambridge University Press, 2007.

LEROUX, Marcel. Global warming: myth or reality? The erring ways of climatology. Chichester, Praxis, 2005.

LINDZEN, Richard S. Some coolness concerning global warming. In: Bulletin of the American Meteorological Society, n. 71, p. 288-299, 1990a. 24, p. 424-427, 1990b.

Some remarks on global warming. In: Environmental Science and Technology, $\mathrm{n}$.

A skeptic speaks out. In: EPA Journal, n. 16, p. 46-47, 1990c.

Some uncertainties with respect to water vapor's role in climate sensitivity. Proceedings of NASA Workshop on the Role of Water Vapor in Climate Processes, October 29 November 1, 1990 in Easton, Maryland (D.O'C. Starr and H. Melfi, editors), 1991.

Regulation, p. 87-98, Spring 1992.

Global warming: the origin and nature of the alleged scientific consensus. In:

LINDZEN, Richard S.; CHOU, Ming-Dah; HOU, Arthur Y. Does the Earth have an adaptive infrared iris? In: Bulletin of the American Meteorological Society, vol. 82, ${ }^{\circ} 3$, março de 2001, p. 417-432.

SPENCER, Roy W. Climate confusion. New York, Encounter Books, 2008.

VIANELLO, Rubens Leite; ALVES, Adil Rainer. Meteorologia básica e aplicações. Viçosa, Editora da Universidade Federal de Viçosa, 1991. 